\title{
Atribuição de Acessibilidade à Fotografia através da Restituição e Desconstrução da Tridimensionalidade
}

\author{
Attribution of accessibility to photography through the restitution and deconstruction of three- \\ dimensionality
}

\author{
Monica Veiga \\ GEGRADi / FAURB / UFPel, Brasil \\ monika_veiga@hotmail.com \\ Adriane Borda \\ GEGRADi / DAURB / FAURB / UFPel, Brasil \\ adribord@hotmail.com
}

\author{
Francisca Michelon \\ Museologia / ICH / UFPel, Brasil \\ fmichelon.ufpel@gmail.com \\ Tatiana Lebedeff \\ Centro de Letras e Comunicação / UFPel, Brasil \\ tblebedeff@gmail.com
}

\begin{abstract}
This paper describes the experiments that are being developed to support an inclusive or accessible exposition of photographs. Physical three dimensional models are being developed using 3D printing technologies to allow tactile experience. The method being structured for this production is registered. It includes the use of the concept of games seeking to work with the purpose of decomposition of information which is recommended by the inclusive communication literature.
\end{abstract}

Keywords: Tactile mock-up; Accessibility; Visual Impairment; Museum; Assistive technology.

\section{Introdução}

Percebe-se que a inclusão cultural, e a acessibilidade como um caminho para promovê-la é um tema contemporâneo. Considerase que este decorre de uma postura reflexiva, a qual entende a sociedade como uma trama de diversidades. Nela, todos os sujeitos possuem o direito de serem incluídos e de terem equidade nas suas condições de participação.

Neste contexto, a proposta de um museu contemporâneo, segundo o Estatuto dos Museus (2009), é de proporcionar experiências de aprendizagem a qualquer momento para qualquer indivíduo.

Este trabalho é parte de um conjunto de experimentos que busca estruturar uma exposição inclusiva de fotografias em um espaço museal. Tais experimentos se utilizam do princípio de desenho universal (SERPRO, 2007) aplicado a um acervo de fotografias, da realização de audiodescrições das mesmas e da produção de esquemas táteis para traduzi-las aos portadores de deficiência visual. Com isto busca-se constituir instrumentos com potencial comunicativo, cada um deles capaz de, na sua associação com os demais, operar como intensificador dos sentidos. Investiga-se a multisensorialidade, enquanto resultado do emprego de diferentes recursos. De como ela pode ser usada para comunicar a qualidade memorial do patrimônio em ambientes que tanto propiciem o compartilhamento como proponham a apropriação da informação em benefício do conhecimento. (Ferreira, 2013).
Sendo assim, o contexto deste trabalho se refere à investigação de novas formas expográficas, particularizando o relato no âmbito da produção de esquemas táteis a partir de fabricação digital.

Apesar das diretrizes serem claras, o processo de adequação à acessibilidade das instituições museológicas parece complicado, tanto em relação ao espaço arquitetônico que as abriga, quanto em relação à maneira que se disponibilizam os acervos propriamente ditos. Este fato fica mais evidente quando nos referimos aos deficientes visuais, questionando-se como os acervos dos museus podem ser apresentados de maneira adequada a este público.

Ao propor representações táteis relativas a acervos museológicos, geradas também por fabricação digital, Pupo (2011) comenta o cerne desta problemática. Refere-se ao fato de que raramente é permitido que se toque em obras de coleções de museus de arte. Destacando que é o discurso sobre a preservação das peças para as gerações futuras que faz com que a política 'anti-toque' seja mantida.

A problemática estabelecida no escopo deste trabalho pode se apoiar em Pupo (2011) no que diz respeito ao tipo de tecnologia empregada. Entretanto, diferencia-se para o propósito de atribuir acessibilidade à compreensão de uma foto, um elemento bidimensional. Faz-se necessário constituir estratégias para descrevê-la a partir de modelos táteis. 
Segundo Pallasmaa (2011), a visão e a audição hoje são os sentidos socialmente privilegiados, enquanto os outros três são considerados resquícios sensoriais arcaicos, com uma função meramente privada e, em geral, são reprimidos pelo código cultural. A respeito deste problema no contexto museológico, Vieira et al (2012) afirma que esta repressão dos sentidos torna os espaços menos ricos em sensações e de mais difícil reconhecimento para os invisuais.

Para usufruir da informação disponível o público referido depende de tecnologias assistivas. Segundo Bersch (2005), tais tecnologias podem ser definidas por todo e qualquer item, equipamento ou parte dele, produto ou sistema fabricado em série ou sob medida, utilizado para aumentar, manter ou melhorar as capacidades funcionais das pessoas com deficiência. Ou ainda para EUSTAT (1999), como aquilo que engloba todos os produtos e serviços capazes de compensar limitações funcionais, facilitando a independência e aumentando a qualidade de vida das pessoas com deficiência e pessoas idosas.

A partir destas considerações, este trabalho se caracteriza pelo propósito de estruturação de tecnologias assistivas para promover a inclusão cultural em exposições museológicas de fotografias.

\section{Materiais e métodos}

O caso particularizado para o estudo refere-se à produção de modelos táteis de fotografias para uma exposição, a qual se configura como primeiro passo para a construção de um novo Museu. Este, sob a responsabilidade da Universidade Federal de Pelotas (UFPel), adota os preceitos contemporâneos de inclusão. A exposição contempla um acervo de vinte fotografias, relativas à história de ocupação de um patrimônio industrial da cidade de Pelotas, um frigorífico, atualmente sede do Campus Porto da UFPel.

Para esta produção foram delimitadas fundamentalmente cinco etapas de trabalho: de revisão bibliográfica, de desenvolvimento do projeto dos modelos táteis para cada fotografia, de execução do projeto, de experimentação e validação.

Junto à etapa de revisão, e no campo das teorias da comunicação, compreendeu-se a partir de Neves (2011) que nem tudo que se vê interessa para a construção do sentido, e desta maneira, "toda descrição requer seleção" (Neves, 2011, p.49). Entendendo-se com isto que a representação tátil não necessita ser uma réplica do original. Para Vieira et al (2012), a informação inserida no modelo deve ser selecionada, para facilitar a compreensão e facilitar a leitura tátil. Para RNIB and vocaleyes (2003), a elaboração da representação pode implicar a simplificação, a alteração, a adaptação ou a distorção do original para transmitir as características mais importantes contidas na imagem visual. Desta maneira, este processo pode resultar numa representação tátil significativamente diferente da imagem visual. Ainda a partir de Neves (2011), compreende-se um pouco mais sobre a necessidade de identificar os elementos mínimos de informação para que possam ser explicados individualmente. Elementos complexos devem ser descritos em etapas, adicionando-se aos poucos a informação para finalmente promover a percepção do todo.

Teshima (2010) considera que as pessoas com deficiência visual podem reconhecer as formas dos objetos tridimensionais (3D) por tocá-los. No entanto, observa a dificuldade de reconhecer estas formas através de figuras em relevo (2,5D).

Frente a isto, considera-se necessário, para a exposição de fotografias, promover o aprendizado da transformação da geometria de um elemento tridimensional quando submetido à projeção sobre um espaço bidimensional. Entende-se que a complementação de dados entre as representações em 3D, indicando-se o ponto de vista de obtenção da fotografia, e a representação 2,5D facilita a descrição da fotografia. A redundância de informações na construção da imagem mental é positiva.

Ainda na etapa de revisão, a partir de Celani e Pupo (2008) foi possível contextualizar a tecnologia de impressão 3D disponível para realizar os experimentos no âmbito deste trabalho. Caracteriza-se por um método de produção aditiva, admitindo como matéria prima para a impressão o termoplástico. Este é derretido para configurar modelos a partir da deposição de camadas, constituindo-os com resistência e conforto para a experiência tátil.

A etapa de desenvolvimento do projeto tem envolvido a estruturação de estratégias pedagógicas e tecnológicas. O conhecimento da Perspectiva tem permitido planejar a lógica para decompor a informação e com isto estruturar as estratégias pedagógicas. Dentre elas realiza-se a restituição da tridimensionalidade do espaço representado na fotografia e, logo, a explicação de como esta geometria se transforma por procedimentos projetivos. Uma sequencia de modelos deve ser capaz de promover a construção de uma imagem mental. Esta decomposição da informação está sendo associada a uma dinâmica de jogos, atribuindo assim um caráter lúdico aos modelos táteis, sempre que possível. O estudo também foi apoiado por técnicas digitais de fotogrametria para facilitar a obtenção de informações para o processo de modelagem tridimensional. Em termos tecnológicos, e em função de que o processo de apropriação das técnicas de impressão 3D está sendo motivado especialmente pelo desenvolvimento deste trabalho, tem-se estudado a compatibilidade de tipos de modelos digitais com os limites impostos pelas técnicas de impressão disponíveis. Desde as dimensões da área de impressão, que no caso tem-se uma área máxima de $18 \times 18 \times 12 \mathrm{~cm}$, à lógica de adição do material para compor o modelo. Durante todo o processo de produção, registram-se os parâmetros adotados para a impressão. Os modelos digitais para serem impressos devem ser modelos sólidos e não de superfície, sendo que se pode controlar o grau de preenchimento do modelo. Isto para garantir rigidez estrutural e também economia de material. 
A lógica de preenchimento desta tecnologia pode ser exemplificada da seguinte maneira: para imprimir um copo é necessário estabelecer um número $X$ de camadas para o fundo; um perímetro com número $Y$; um preenchimento de zero\% e nenhuma camada de cobertura. Se o número das camadas de cobertura e a porcentagem do preenchimento não forem zerados, o resultado será uma peça maciça.

Pode-se considerar que a etapa de execução dos modelos quase que se fundiu com a etapa de projeto, especialmente por ter coincidido com o estágio inicial de apropriação da tecnologia. Muito dos problemas de impressão tem exigido a reestruturação das técnicas de modelagem estabelecidas no projeto. Deve-se destacar que ao longo deste processo contou-se com a parceria da própria empresa fabricante da máquina de impressão (www.cliever.com). A máquina utilizada para os experimentos é do primeiro lote de produção desta empresa. O relato das dificuldades de apropriação junto à empresa certamente provocaram alguns reajustes, seja na interface ou no próprio equipamento. Por exemplo, sobre a própria diferença de desempenho da máquina ao trabalhar com o termoplástico de uma cor ou outra.

Apesar da etiqueta nos rolos de PLA indicar que a temperatura a ser utilizada seja entre $165^{\circ}$ e $185^{\circ} \mathrm{C}$, foi percebido que cada cor se comporta de maneira diferente. Esta hipótese foi levantada nos primeiros estágios de apropriação da técnica e levada até o fabricante, que confirmou o fato e sugeriu novos valores de temperatura para cada cor. A tabela 1 registra estas constatações.

Tabela 1. Relação de cores e suas respectivas temperaturas ideais de trabalho de acordo com o fabricante da máquina.

\begin{tabular}{|c|c|c|}
\hline Cor do filamento & Densidade & Temperatura ideal \\
\hline Branco & $1.24 \mathrm{~g} / \mathrm{cc}$ & 185 ㅇ \\
\hline Amarelo & $1.24 \mathrm{~g} / \mathrm{cc}$ & 180 - \\
\hline Verde & $1.24 \mathrm{~g} / \mathrm{cc}$ & 180 - \\
\hline Azul & $1.24 \mathrm{~g} / \mathrm{cc}$ & 180 o \\
\hline Vermelho & $1.24 \mathrm{~g} / \mathrm{cc}$ & 175 을 \\
\hline Preto & $1.24 \mathrm{~g} / \mathrm{cc}$ & 175 ㅇ \\
\hline
\end{tabular}

A partir desta constatação passou a ser necessário fazer o reajuste de temperatura do equipamento a cada troca de cor para aceitar diferenças mínimas de ponto de fusão do material.

Outra questão importante refere-se aos parâmetros de configuração de impressão, que definem o preenchimento interno e o acabamento das camadas externas do produto final. Como já foi exemplificado anteriormente, numa impressão, as camadas externas podem ser de três tipos: de base, que corresponde ao número camadas horizontais, ou, o que seria o fundo do copo; de perímetro, que corresponde às camadas verticais, no caso, o corpo do copo; de topo ou cobertura, que corresponde ao que poderia ser uma tampa para este exemplo.

Atualmente, após inúmeras atualizações do software, é possível determinar o número de camadas de todos os tipos, chegando a uma espessura mínima de uma camada de três décimos de milímetro. Quanto ao preenchimento, era possível ser feito a partir de um padrão concêntrico, uma malha ortogonal ou de alvéolos, (chamados de honeycomb). Atualmente, o padrão adotado é o honeycomb e o cálculo das dimensões desta malha é feito automaticamente a partir do percentual de preenchimento determinado pelo usuário.

É importante ressaltar que deve-se evitar que o diâmetro de cada alvéolo seja maior do que 12 milímetros. Caso seja inevitável, camadas extra de cobertura serão necessárias para compensar o acabamento da superfície.

Nesta etapa de execução utiliza-se outra ferramenta de apoio para detectar possíveis inconsistências do modelo digital que possam impossibilitar a fabricação da peça: o aplicativo netfabb (http://www.netfabb.com/), que avalia os arquivos de extensão .STL, padrão para impressão, identificando os pontos de conflito e opções de reparo.

As etapas de experimentação e validação foram planejadas com a seguinte sequencia: inicialmente um teste com especialistas na área; logo, com deficientes visuais, seguindo-se com o público em geral, buscando-se também particularizar estudantes de arquitetura em fases do estudo de perspectiva.

\section{Resultados}

Até o momento foram realizados os projetos e a execução de modelos táteis representativos para quatro fotografias (aqui denominadas como fotos 1, 2, 3 e 4).

\section{Modelos táteis para a descrição da Foto 1}

A foto 1 , à esquerda da fig. 1 , registra a imagem de uma chaminé sendo vista através de uma janela. Parece querer enfatizar a característica industrial do espaço e o seu estado de abandono. 0 ponto de vista evidencia as deformações provocadas pelo efeito da imagem em perspectiva. Para descrevê-la, em sua geometria, produziu-se uma sequencia de modelos, ilustrada também na figura 1. Da esquerda pra direita, após a foto, tem-se o modelo do conjunto dos objetos arquitetônicos envolvidos, a ser impresso na escala 1:500. A seguir, o modelo do conjunto dos elementos fundamentais: a janela e a chaminé, a ser impresso na escala 1:125. Com ambos busca-se promover a percepção de posições e tamanhos relativos, indicando a localização dos pontos de vista. Na sequencia, a imagem dos modelos já impressos, demonstrando a decomposição em duas partes. Com isto tem-se a possibilidade de compreender o efeito de deformação da chaminé sem a interferência da grade da janela. O tipo de modelo da direita intenciona agregar mais informação. Além da geometria, tenta informar sobre a aparência do conjunto dos elementos, produto do fenômeno de interação entre luz e matéria. Entretanto, como já identificado na etapa de revisão, a quantidade de informação e imprecisão do limite do contorno de cada uma das formas, pode 
comprometer a compreensão pelo tato. Entende-se que a hipótese de validade deste modelo se justifica por fazer parte de tal sequencia, em um processo adicional de informações. Para a obtenção deste tipo de modelo a fotografia foi traduzida em níveis de cinza, sobre os quais foram atribuídas diferenças de profundidade.

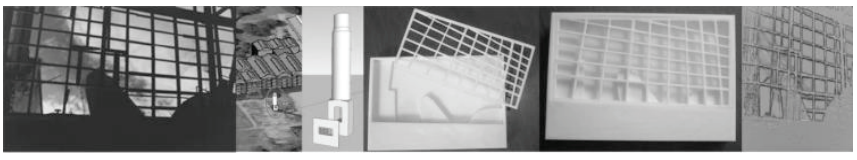

Figura 1: à esquerda, Foto 1 e na sequencia o conjunto de modelos táteis projetados para a sua descrição. Fonte: foto 1: acervo do museu/UFPel; demais imagens: autoras.

\section{Modelos táteis para a descrição da Foto 2}

$\mathrm{Na}$ foto 2, à esquerda da fig. 2 o ponto de vista da foto permite observar as coberturas das edificações e destaca os contrastes entre novos materiais com as paredes de cimento penteado, técnica de revestimento já não utilizada mais e que muito caracteriza a arquitetura industrial da cidade.

Para entender a geometria da imagem, faz-se necessário explicitar as posições relativas entre os elementos envolvidos: ponto de vista do fotógrafo e as coberturas fotografadas. Para isso, primeiramente foi elaborada representação 2,5D para ilustrar o enquadramento da foto e em seguida, uma maquete do conjunto dos edifícios para que se compreenda a geometria dos telhados em verdadeira grandeza, a fim de comparar o ponto de vista do primeiro modelo, com a marcação da posição do fotógrafo no segundo.
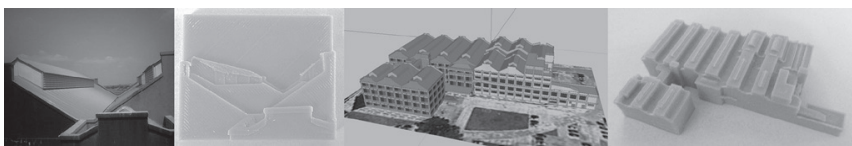

Figura 2: à esquerda, Foto 2 e na sequencia a representação 2,5D, o modelo digital da representação $3 D$ e a peça impressa a partir deste modelo. Fonte: foto 2: acervo do museu/UFPel; demais imagens: autoras.

\section{Modelos táteis para a descrição da Foto 3}

Já foto 3, à esquerda da fig. 3, ilustra um galpão com uma porta larga nos fundos, janelas nas paredes laterais e nenhuma cobertura. Nele, encontram-se duas fileiras de pilares. Neste caso a representação 2,5D parece um pouco mais complexa do que nas outras fotografias apresentadas, por conta da confusão causada pela quantidade de pilares dispostos em diferentes profundidades do ambiente. Logo, pensou-se em duas hipóteses: a primeira, uma representação simples na qual todos os elementos estão em relevo numa peça inteiriça, como apresentado no último quadro da figura3. Já na segunda hipótese, ainda em fase de projeto, a estratégia adotada funciona como um quebra-cabeça que pretende representar a profundidade do espaço em uma peça com sulcos nos quais os pilares podem ser encaixados e removidos.
A representação 3D desta imagem foi modelada a partir de fotogrametria, obtendo-se assim uma maquete do ambiente fotografado, na qual existe uma seta localizando a posição do fotógrafo no instante em que a foto foi tirada, como pode ser visto na figura 3.

Esta representação requer que o modelo seja fatiado em três módulos para que sejam colados depois de prontos, pois a demanda exige uma peça muito maior do que a mesa de impressão pode suportar. O aplicativo reparador netfabb possui uma ferramenta de corte. Porém, muitas vezes ao partir um objeto que foi modelado como um todo, este passa a apresentar mais inconsistências. O ideal é que em casos como este, o objeto já seja fatiado no software em que foi modelado e que se mantenha as três partes no mesmo arquivo. Isso evita que haja pequenas diferenças de escala ao passar o arquivo pelo aplicativo reparador.

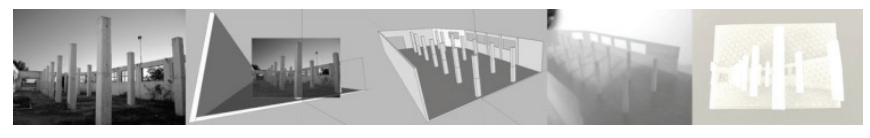

Figura 3: à esquerda, Foto 3 e na sequência a modelagem por fotogrametria; modelo digital da representação 3D; a peça impressa a partir deste modelo; a primeira hipótese de representação 2,5D. Fonte: foto 2: acervo do museu/UFPel; demais imagens: autoras.

\section{Modelos táteis para a descrição da Foto 4}

A foto 4 , à esquerda da fig.4, refere-se à um quadro de madeira utilizado como suporte de ferramentas da antiga fábrica. A ausência das ferramentas e as manchas de suas respectivas marcações são informações relevantes e que devem ser representadas. A princípio foram levantadas duas hipóteses de representação para este caso: a primeira seria de que uma representação 2,5D em baixo relevo poderia representar a falta das ferramentas. Porém, logo considerou-se que o quadro deveria conter efetivamente as ferramentas. Assim seria mais fácil informar sobre suas formas e a maneira como estavam dispostas sobre o suporte de madeira. Esta hipótese então, seria a de disponibilizar o modelo 2,5D, informando através do discurso (impresso ou falado) que o alto relevo está sinalizando que todas as ferramentas deixaram apenas a sua marca, a qual reporta a um grande período de tempo em que tais ferramentas estiveram ali depositadas, ao término de jornadas de trabalho, como pode ser visto na figura 4. Tempos depois, foi levantada uma terceira hipótese, que inclui uma das ferramentas avulsa, para encaixar na base, completando o quadro.

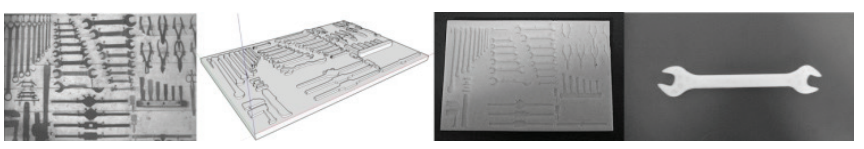

Figura 4: à esquerda, Foto 4 e na sequência o modelo digital da representação 3D; a peça impressa a partir deste modelo; a peça complementar que se encaixa à principal. Fonte: foto 4: acervo do museu/UFPel; demais imagens: autoras. 


\section{Considerações finais}

Promover o aprendizado em um contexto museal cumpre com os objetivos deste tipo de instituição. A tentativa de explicar a fotografia, e consequentemente o fenômeno da perspectiva, para os invisuais promoveu a construção de materiais didáticos que podem auxiliar um público bem mais amplo a também compreender tal processo projetivo.

Talvez o mais difícil no processo de apropriação da tecnologia, a princípio, tenha sido a reeducação do raciocínio na etapa de modelagem. Modelar para imprimir exige uma estratégia diferente do modelar para apresentar imagens. É preciso considerar o método de impressão e as limitações da máquina.

Deve-se destacar que todo este trabalho depende do conjunto de ações, de audiodescrição e de pessoas que facilitem presencialmente a experiência tátil. Desta maneira, os tipos de modelos produzidos se constituem como infraestrutura para as ações museais inclusivas.

\section{Agradecimentos}

Este trabalho contou com subsídios de bolsa de extensão através do programa PROEXT e conta atualmente com bolsa de iniciação tecnológica, do CNPQ, agradecendo-se assim às instituições responsáveis. Se agradece também à comunidade europeia, que através do Programa ALFA III, e no âmbito do Projeto ALFA GAVIOTA, financiou equipamentos que deram suporte aos estudos realizados. Os materiais de consumo foram financiados também pelo programa PROEXT/UFPel.

\section{Referências}

BERSCH, R., (2005). Introdução à Tecnologia Assistiva. Disponível em: http://www.assistiva.com.br/Introducao\%20TA\%20Rita\%20Bersch.p df Acesso em maio de 2013.

Cliever Tecnologia - Impressoras 3D. Disponível em: www.cliever.com.br Acesso em setembro de 2013
Estatuto dos museus 2009. BRASIL. Texto da Lei $n^{\circ} 11904$, de 14 de janeiro de 2009. Disponível em: www.planalto.gov.br/ccivil_03/_Ato20072010/.../L11904.htm. Acesso em 05 de junho de 2012.

EUSTAT, 1999. Empowering Users Through Assistive Technology. Disponível em http://www.independentliving.org/docs1/eustat99.html Acesso em setembro de 2013.

Netfabb - reparador de modelos 3D. Disponível em: http://www.netfabb.com/ Acesso em setembro de 2013

NEVES, Josélia (2011). Imagens que se ouvem: Guia de Audiodescrição. Instituto Politécnico de Leiria \& Instituto do CInema e Audiovisuais, Leiria.

PALLASMAA, Juhani (2011). OS OLHOS DA PELE: A arquitetura e os sentidos. Bookman, Porto Alegre.

PUPO, R., ARANDA, I. M., (2011). Sentir um quadro. Em XV Congreso de la sociedad iberoamericana de gráfica digital. SIGRADI 2011. Disponível em:

http://cumincades.scix.net/data/works/att/sigradi2011_347.content. pdf acesso em setembro de 2013.

RNIB and vocaleyes (2003).The Talking Images Guide Museums, galleries and heritage sites: improving access for blind and partially sighted people.RNIB and vocaleyes, Londres. Disponível em: http://view.officeapps.live.com/op/view.aspx?src=http\%3A\%2F\%2Fw ww.rnib.org.uk\%2Fprofessionals\%2FDocuments\%2Ftalking_images_g uide.doc acesso em agosto de 2013

SERPRO - Serviço Federal de Processamento de dados. Acessibilidade e "Universal Design". Disponível em http://www.serpro.gov.br/acessibilidade/duniversal.php Acesso em dezembro de 2007.

TESHIMA, Yoshinori. Three-dimensional tactile models for blind people and recognition of $3 \mathrm{D}$ objects by touch: introduction to the special thematic session. In: 12th International Conference on Computers Helping People with special needs. Viena - Austria, 14 a 16/07/2010. ICCHP'10 Proceedings. Springer- Verlang Berlin, Heidelberg, 2010. Pág $513 \quad$ - $514 . \quad 5 i s p o n i ́ v e l \quad$ em: http://staff.aist.go.jp/yoshinori.teshima/sts acesso em março de 2012

VIEIRA,A., AGUIAR, J., PEDRO, J.B. (2012) O que os olhos não vêem mas o coração sente - O reconhecimento do espaço arquitetônico por invisuais. Disponível em: http://fautl.academia.edu/AdrianaVieira acesso em julho de 2013 